\title{
Syntheis of Polyamide-Imides Containing Ether and Sulfonamide Groups
}

\author{
Atanu RAY, Yedidi V. RAO, Vijay K. BHATTACHARYA, \\ and Sukumar MAITI \\ Polymer Division, Materials Science Centre, \\ Indian Institute of Technology, Kharagpur 721302, India
}

(Received July 28, 1982)

\begin{abstract}
KEY WORDS Polyamide-Ether-Imide / Polyamide-Ether-ImideSulfonamide / $\mathrm{N}$-( $p$-Carboxyphenyl)trimellitimide / $\mathrm{N}$-Sulfotrimellitimide / 4,4'-[Isopropylidenebis(1,4-phenyleneoxy)]dianiline / N,N-Dimethylformamide / $N, N$-Dimethylacetamide / 1-Methyl-2-pyrrolidone / 4-Aminobenzoic Acid / Sulfamic Acid / Trimellitic Anhydride /
\end{abstract}

Polyamide-imides (PAI) offer a class of resins which combine the advantage of high temperature stability with ease of processability. ${ }^{1-6}$ Various approaches have been carried out successfully in the synthesis of PAIs. The thionyl chloride activated low temperature polycondensation technique for the synthesis of co-polyesters and co-polyamides has been reported by Imai et al., ${ }^{7}$ and has been extended to the synthesis of polyamide-imides ${ }^{8}$ and polyester-imides $^{9}$ at our laboratory. In the present communication, we report the synthesis of PAIs from diacids having preformed imide groups with an ethereal diamine by low temperature polycondensation in the presence of thionyl chloride in polar solvents. Physical, chemical and certain other properties of the polymers are also described.

\section{EXPERIMENTAL}

\section{Materials}

Trimellitic anhydride (TMA) (Tokyo Kasei Industries, Japan) was used following its recrystallization from acetic anhydride. $p$-Aminobenzoic acid (BDH, India), sulfamic acid (BDH, India) and bisphenol A (BDH, England) were purified by recrystallization from ethanol. Chlorobenzene (BDH, India) was distilled before use. All other solvents were purified following standard procedures. ${ }^{11}$

\section{Monomer Synthesis}

$N$-( $p$-Carboxyphenyl)trimellitimide (I) was prepared from trimellitic anhydride and $p$-aminobenzoic acid following the procedure of Maiti $e t$ $a l .{ }^{12}$

$N$-Sulfotrimellitimide (IV) was prepared by the reaction of TMA with sulfamic acid as reported earlier. ${ }^{13}$

The ethereal diamine (II) was prepared by the reaction of $p$-chloronitrobenzene with bisphenol-A following the procedure of Santappa et al. ${ }^{10}$

$p$-Chloronitrobenzene was prepared by nitration of $p$-chlorobenzene following the standard procedure. ${ }^{14}$

The strucrure of monomers I, II, and IV was confirmed by elemental analysis and IR spectroscopy.

\section{Polymer Synthesis}

The diacids I and IV, were reacted with II at low temperature in the presence of thionyl chloride to produce PAIs. A typical example is as follows: $3.11 \mathrm{~g}(10 \mathrm{mmol})$ of $\mathrm{I}$ in $25 \mathrm{ml}$ of $N, N-$ dimethylformamide (DMF) were placed in a three necked flask fitted with a stirrer, a thermometer and a nitrogen purge tube. The solution was cooled to $-5^{\circ} \mathrm{C}$ and $2.38 \mathrm{~g}(20 \mathrm{mmol})$ of thionyl chloride were added with stirring. $4.10 \mathrm{~g}(10 \mathrm{mmol})$ of II and $1.58 \mathrm{~g}(20 \mathrm{mmol})$ of pyridine were then added to the mixture which was stirred for $9 \mathrm{~h}$ at $0-5^{\circ} \mathrm{C}$ and 
finally for $1 \mathrm{~h}$ at room temperature $\left(\sim 30^{\circ} \mathrm{C}\right)$. At the end of the reaction, the mixture was poured into ice/ water and filtered. The product was washed several times with chloroform and purified by dissolving in DMF and reprecipitation by methanol.

The repeat units of the polymers III and $\mathbf{V}$ were characterized by elemental analyses (nitrogen and sulfur) and IR spectroscopy (Perkin-Elmer 237B Spectrophotometer, $\mathrm{KBr}$ pellet). X-ray measurements were made with DORN I (USSR) X-ray
Diffractometer using Ni-filtered $\mathrm{Cu}-K_{\alpha}$ radiation. Thermal analysis was carried out (Hungarian MOM Derivatograph of Paulik Paulik Erdey system) in air, at a heating rate $10^{\circ} \mathrm{C} \mathrm{min}-1$.

\section{RESULTS AND DISCUSSION}

PAIs prepared by thionyl chloride-activated polycondensation involve the diacid chloride as an intermediate compound as shown in the scheme.<smiles>CC(C)(c1ccc(Oc2ccc(N)cc2)cc1)c1ccc(N2C(=O)c3ccc(C(=O)O)cc3C2=O)cc1</smiles><smiles>CC(C)(C)Nc1ccc(Oc2ccc(C(C)(C)c3ccc(Oc4ccc(NC(=O)c5ccc(N6C(=O)c7ccccc7C6=O)cc5)cc4)cc3)cc2)cc1</smiles><smiles>CC(C)(C)Nc1ccc(Oc2ccc(C(C)(C)c3ccc(Oc4ccc(NS(=O)(=O)N5C(=O)c6ccc(C(C)(C)C)cc6C5=O)cc4)cc3)cc2)cc1</smiles>

(V)

Table I. Yield and physical properties of the polyamide-imides

\begin{tabular}{|c|c|c|c|c|c|c|c|c|c|}
\hline \multirow{2}{*}{$\begin{array}{l}\text { Polymer } \\
\text { code name }\end{array}$} & \multirow{2}{*}{$\begin{array}{c}\text { Solvent } \\
\text { used for } \\
\text { polymerization }\end{array}$} & \multirow{2}{*}{$\frac{\text { Yield }}{\%}$} & \multirow{2}{*}{$\begin{array}{c}\begin{array}{c}\text { Inherent }^{\mathrm{a}} \\
\text { viscosity }\end{array} \\
\mathrm{dl} \mathrm{g}^{-1}\end{array}$} & \multirow{2}{*}{$\frac{\text { Density }}{\mathrm{g} \mathrm{cm}^{-3}}$} & \multirow{2}{*}{$\frac{T_{\mathrm{m}}^{\mathrm{b}}}{{ }^{\circ} \mathrm{C}}$} & \multicolumn{2}{|c|}{ Nitrogen $/ \%$} & \multicolumn{2}{|c|}{ Sulfur $/ \%$} \\
\hline & & & & & & Calcd & Found & Calcd & Found \\
\hline \multirow[t]{2}{*}{ III } & DMF & $68-70$ & 0.16 & 1.18 & - & 6.13 & 6.57 & - & - \\
\hline & NMP & $75-76$ & 0.18 & 1.18 & 365 & 6.13 & 6.42 & - & - \\
\hline \multirow[t]{2}{*}{$\mathbf{V}$} & DMF & $61-63$ & 0.13 & 1.17 & - & 6.51 & 6.79 & 4.96 & 4.72 \\
\hline & NMP & $66-67$ & 0.15 & 1.18 & 357 & 6.51 & 6.28 & 4.96 & 4.68 \\
\hline
\end{tabular}

a Measured in DMF ( 0.5 weight $\%$ solution) at $30^{\circ} \mathrm{C}$.

b Calculated from DTA curves (Figure 2). 
Polyamide-Imides with Ether and Sulfonamide Groups

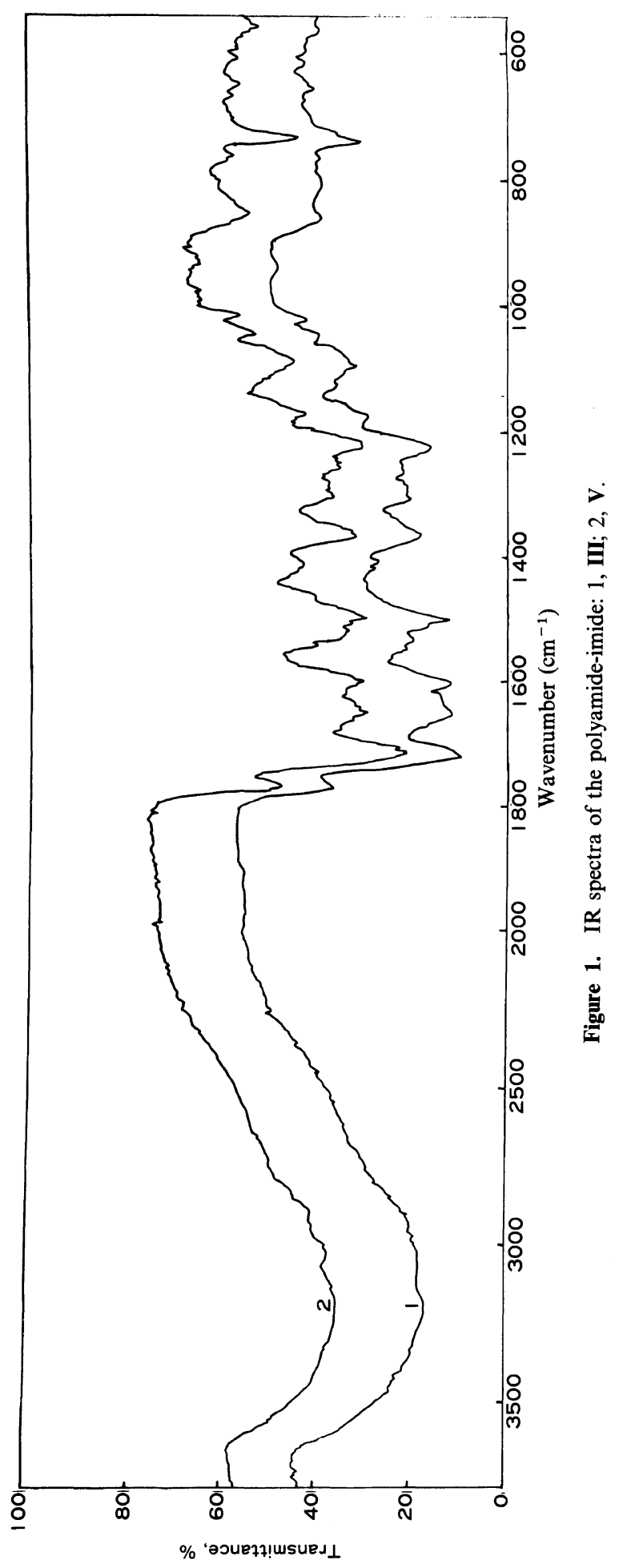




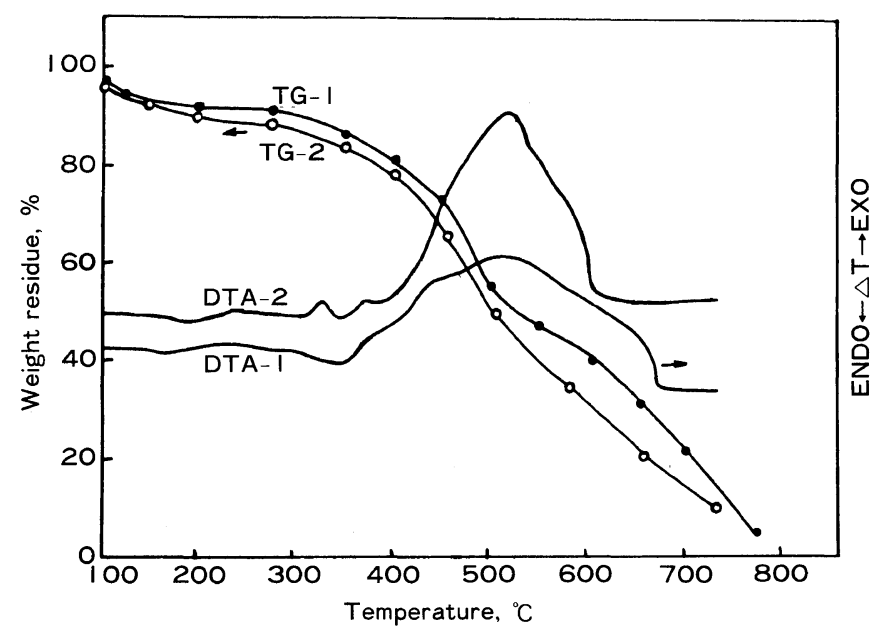

Figure 2. Differential thermal analysis (DTA) and thermogravimetric analysis (TGA) of III, (DTA-1, TG-1); V, (DTA-2, TG-2) in air at a heating rate, $10^{\circ} \mathrm{C} \mathrm{min}^{-1}$.

It was found that $N$-methyl-2-pyrrolidone (NMP) and DMF were suitable solvents for this polycondensation reaction. Although pyridine was used as the acid acceptor, other bases such as triethylamine may also be used. The molecular weight of the polymer may be controlled by changing the reaction conditions including solvents and preferably by the use of a suitable catalyst.

The physical properties of the resulting polyamide-imides are shown in Table I. The inherent viscosity of the polymers was found to be low (Table I), indicating low molecular weights. However, it is observed that solvents with higher polarity increases the overall yield and the molecular weight of the polymers. Using NMP as a solvent, the yield and inherent viscosity of both polymers are improved over those in DMF.

The IR spectra of the PAIs III and $V$ are shown in Figure 1.

The polymers were found to be soluble in highly polar solvents such as DMF, $N, N$-dimethylacetamide, NMP, dimethyl sulfoxide, conc. $\mathrm{H}_{2} \mathrm{SO}_{4}$ etc. but insoluble in benzene, toluene, xylene, carbon tetrachloride, chloroform, methanol, ethanol, chlorobenzene, nitrobenzene etc. Similar solubilities have been reported by Kurita et al. ${ }^{5}$ as well as Maiti and co-workers. ${ }^{8,9,12}$

$\mathrm{X}$-Ray diffraction diagrams of these polymers showed no sharp peaks, indicating the polymers to be amorphous. The higher solubility and lower density of the polymers corroborate this.
Differential thermal analysis (DTA) and thermogravimetric analysis (TGA) for polymers in air are shown in Figure 2. From the DTA curves, these polymers seem to be fairly thermostable. The degradation started at $370^{\circ} \mathrm{C}$ for $\mathrm{III}$ and at $362^{\circ} \mathrm{C}$ for V. The melting temperature, $T_{\mathrm{m}}$, of polymers III and $\mathbf{V}$ appeared to be 365 and $357^{\circ} \mathrm{C}$, respectively (Figure 2). The TGA curves show that both the polymers undergo an initial weight loss of $5-6 \%$ at $100-110^{\circ} \mathrm{C}$, due possibly to loss of moisture or entrapped solvents. Subsequently, there is only a $4-6 \%$ weight loss at $350^{\circ} \mathrm{C}$ and the maximum decomposition occurs at $400-600^{\circ} \mathrm{C}$ for either polymers. Similar thermal behavior was also observed in other polyamide-imides reported earlier. ${ }^{8,9,15}$

Acknowledgements. The authors wish to thank Dr. N. Roychoudhuri for making the thermal measurements and Tokyo Kasei Industries, Japan for providing the TMA sample.

\section{REFERENCES}

1. G. M. Bower and L. W. Frost, J. Polym. Sci., A, 1, 3135 (1963).

2. J. Fontan, Chem. Kunstot-Aktuell, 32, 225 (1978); Chem. Abstr., 92, 7091 (1980).

3. De. Abajo, J. P. Gabarda, and J. Fontan, Angew. Makromol. Chem., 71, 143 (1978).

4. H. Lee, D. Stoffey, and K. Neville, "New Linear Polymers," McGraw-Hill, New York, 1967, p 175.

5. K. Kurita, H. Itoh, and Y. Iwakura, J. Polym. Sci., 
Polym. Chem. Ed., 16, 779 (1978).

6. M. Fujimoto, T. Oishi, M. Momio, and S. Murata, Nippon Kagaku Kaishi, 9, 1465 (1976); Chem. Abstr., 88, 38179 (1978).

7. M. Ueda, S. Aoyama, M. Konno, and Y. Imai, Makromol. Chem., 179, 2089 (1978).

8. S. Das and S. Maiti, Makromol. Chem. Rapid Commun., 1, 403 (1980); A. Ray, S. Das, and S. Maiti, ibid., 2, 333 (1981); S. Maiti and A. Ray, ibid., 2, 649 (1981).

9. A. Ray, V. K. Bhattacharya, and S. Maiti, Makromol. Chem. Rapid Commun., 3, 205 (1982).

10. M. J. Nanjan, M. Balasubramanian, K. S. V. Srinivasan, and M. Santappa, Polymer, 18, 411
(1977).

11. D. D. Perrin, W. L. F. Armargo, and D. R. Perrin, "Purification of Laboratory Chemicals," 2nd ed, Pergamon Press, New York, 1980.

12. S. Maiti and S. Das, J. Appl. Polym. Sci., 26, 957 (1981).

13. A. Ray, Y. V. Rao, V. K. Bhattacharya, and S. Maiti, Eur. Polym. J. (communicated, 1982).

14. A. I. Vogel, "Textbook of Practical Organic Chemistry," 4th ed, Longmans, New York, 1978, p 627.

15. S. Maiti and A. Ray, J. Macromol. Sci., Chem., A18, 955 (1982) 